\title{
Vivências e expectativas de gestantes em idade materna avançada com suspeita ou
} confirmação de malformação

\section{Experiences and expectations of pregnant women in advanced maternal age with suspected or confirmed fetus malformation}

\section{Vivencias y expectativas de gestantes en edad materna avanzada con sospecha o confirmación de malformación}

Recebido: 19/07/2017

Aprovado: $12 / 03 / 2018$

Publicado: 01/08/2018

\section{Camila Rebouças Fernandes ${ }^{1}$} Aline de Carvalho Martins ${ }^{2}$

0 presente estudo tem como objetivo investigar as vivências e as expectativas de mulheres em idade materna avançada, grávidas de bebês com diagnóstico suspeito ou confirmado de malformação. Trata-se de uma pesquisa qualitativa, descritiva e exploratória, realizada entre janeiro e junho de 2016, com análise de conteúdo, na modalidade temática. Foram entrevistadas sete gestantes com 35 anos ou mais, acompanhadas no ambulatório de pré-natal de uma unidade de saúde pública, federal, de referência para risco fetal. Evidenciou-se duas categorias: "O constrangimento de receber e compartilhar a notícia"; e "Receios quanto ao futuro". Verificou-se que existem tensões das mulheres quanto à aceitação social da criança, incertezas quanto ao futuro profissional e expectativas de sobrecarga nos cuidados com a criança. Conclui-se que estas mulheres devem receber atendimento especializado para tratar estas questões.

Descritores: Idade materna; Relações materno-fetais; Gênero e saúde.

This study aims at investigating the experiences and expectations of women in advanced maternal age, pregnant of children with a confirmed or suspected diagnosis of fetus malformation. This is a qualitative, descriptive and exploratory research, conducted from January to July 2016, including content analysis, in the thematic modality. Seven pregnant women were interviewed. Participants had to be 35 years of age or more and be monitoring their situation in the prenatal outpatient clinic of a specific federal public health unit, which is a reference for fetal risks. Two categories came to light: "The embarrassment of receiving and sharing the news"; and "Fears regarding the future". Tensions were found to exist among women regarding the social acceptance of their children, uncertainties regarding their professional future and expectations of overload in the care with the child. The conclusion is that these women should receive specialized care to deal with these issues. Descriptors: Maternal age; Maternal-fetal relations; Gender and health.

El presente estudio tiene como objetivo investigar las vivencias y las expectativas de mujeres en edad materna avanzada, embarazadas de bebés con diagnóstico sospechoso o confirmado de malformación. Se trata de una investigación cualitativa, descriptiva y exploratoria, realizada entre enero y junio de 2016, con análisis de contenido, en la modalidad temática. Fueron entrevistadas siete gestantes con 35 años o más, acompañadas en el ambulatorio de pre-natal de una unidad de salud pública, federal, de referencia para riesgo fetal. Se evidenciaron dos categorías: "El malestar de recibir y compartir la noticia" y "Recelos en cuanto al futuro". Se verificó que existe una tensión en las mujeres en cuanto a la aceptación social del niño, incertezas en cuanto al futuro profesional y expectativas de sobrecarga en los cuidados del niño. Se concluye que estas mujeres deben recibir atendimiento especializado para tratar estas cuestiones.

Descriptores: Edad materna; Relaciones materno-fetales; Género y salud.

1. Assistente Social. Especialista em Saúde da Criança e do Adolescente Cronicamente Adoecidos na modalidade residência multiprofissional. Mestranda em Políticas Públicas em Direitos Humanos pela Universidade Federal do Rio de Janeiro, Rio de Janeiro/RJ/Brasil. ORCID: 0000-0001-5183-5073 Email: camila-fernandees@hotmail.com

2. Assistente Social. Especialista em Controle de Riscos e Agravos à Saúde do Recém-nascido. Especialista em Saúde Maternoinfantil. Mestre e Doutora em Serviço Social. Tecnologista Plena em Saúde Pública da Fundação Oswaldo Cruz, Rio de Janeiro/RJ/Brasil. ORCID: 0000-0002-4663-1380 Email: rjalinemartins@yahoo.com.br 


\section{INTRODUÇÃo}

$\mathbf{0}$ Brasil passa por um processo de transição epidemiológica demográfica

que se torna mais evidente com o aumento do nível de escolaridade das mulheres-mães. Essas transições se construíram historicamente relacionadas à redução da mortalidade infantil, aumento do envelhecimento populacional e diminuição das taxas de fertilidade ${ }^{1}$.

Neste contexto, a chamada idade materna avançada - a gestação em mulheres com idade igual ou superior a 35 anos $^{2}$ - se localiza, apresentando um incremento expressivo no número de nascimentos brasileiros. Se, no país, a partir dos anos 2000 verifica-se um declínio das taxas de natalidade, quando se isola o grupo de mulheres a partir de 35 anos, o que se observa é um incremento de $32 \%$ nos nascimentos após o ano 2000, passando de 275.277 nascimentos no ano 2000, para 364.405 nascimentos em 2014, com um crescimento linear e sistemático após o ano de 20073 .

A maternidade tardia se articula a dimensões sociais, econômicas, políticas e ideológicas, relacionando-se diretamente às alterações no modo de sociabilidade feminina nas últimas décadas. As motivações para adiamento da gestação são diversas e podem se vincular às ambições profissionais que exigem investimento, postergação da época do casamento, estabelecimento de novas uniões afetivas, dificuldades para a fertilidade e o acesso a uma diversificada disponibilidade de métodos contraceptivos ${ }^{4}$.

Esses fatores são decorrentes das mudanças no mundo do trabalho, à medida que a mulher se insere no âmbito público e amplia sua ocupação no mercado de trabalho e alonga seu tempo de formação profissional. Provavelmente, esta tendência irá se manter ${ }^{5}$, o que requererá que os profissionais de saúde estejam preparados para oferecer assistência qualificada a este segmento.

A reprodução feminina tardia impacta diretamente no perfil de saúde e adoecimento infantil. Esta é considerada como gestação de risco por conta das repercussões que apresenta para a vida da mulher e do feto ${ }^{2}$. A gestação a partir dos 35 anos apresenta maiores chances de nascimento de um bebê com malformação ${ }^{6}$.

Um estudo ${ }^{6}$ referente a malformações congênitas e fatores de risco materno em Campina Grande - Paraíba, indicou a idade materna avançada como um fator que pode influenciar na malformação fetal. Neste âmbito, o bebê pode apresentar maiores chances de nascer com malformação e desenvolver, potencialmente, condições crônicas de saúde, reforçando a cronicidade do modo de adoecer de acordo com as transições demográfica e epidemiológica.

Há centralidade da mulher para os cuidados com as crianças, mesmo em um contexto de exercício profissional fora do domicílio $^{7}$. Se o cuidado infantil já é, por excelência, feminino, esta questão tende a se agravar quando se trata de uma criança com condições crônicas de saúde 8 -10.

A malformação congênita pode se caracterizar como uma anomalia morfológica por motivos genéticos, ambientais ou mistos, resultantes de todo defeito presente em um ou vários órgãos ${ }^{11}$. As condições crônicas de saúde se configuram por um período de duração considerado longo, podendo, em alguns casos, se apresentar de forma definitiva ou permanente ${ }^{12}$.

A malformação pode resultar, potencialmente, em condições crônicas de saúde. Quando a malformação fetal resulta em condições crônicas de saúde para a criança, é possível afirmar que a sobrecarga materna tende a aumentar, considerando as demandas específicas apresentadas.

0 presente artigo se justifica através da necessidade de conhecer o perfil e as demandas desse público crescente, constituído pelas gestantes em idade materna avançada, ampliando sua visibilidade para possibilitar serviços condizentes com as suas necessidades e com a sua realidade. Neste contexto, o presente estudo tem como objetivo investigar as vivências e expectativas de mulheres em idade materna avançada, grávidas de bebês com diagnóstico suspeito ou confirmado de malformação. 


\section{MÉTODO}

Estudo de natureza qualitativa, descritiva e exploratória, realizada entre o período de janeiro a junho de 2016 com a análise de conteúdo, modalidade temática ${ }^{13}$.

Participaram deste estudo gestantes acompanhadas pelo ambulatório de pré-natal de uma unidade pública, federal e de referência para gestação de alto risco fetal, com idade igual ou superior a 35 anos e com diagnóstico suspeito ou confirmado de malformação fetal (MFF). Excluiu-se deste estudo, por questões éticas, mulheres cujos fetos fossem considerados incompatíveis com a vida.

A coleta de dados se deu através de entrevistas semiestruturadas. Utilizou-se como estratégia de encerramento da coleta de dados a saturação dos dados, onde as entrevistas deixam de ser realizadas por já não produzirem novas informações ${ }^{14}$.

A pesquisa foi realizada consoante com a Resolução no 466/201215, sendo submetida à apreciação pelo Comitê de Ética em Pesquisa (CEP) e aprovada, recebendo o CAAE 51848015.0.0000.5269. As entrevistadas foram indicadas por nomes fictícios ao longo do estudo, visando preservar o sigilo e a confidencialidade.

0 corpus da pesquisa foi submetido às três fases de estudo do material, que são compostas por pré-análise, exploração do material e análise dos dados obtidos ${ }^{13}$.

\section{RESULTADOS}

Participaram do estudo sete gestantes. 0 perfil dessas mulheres, para ter maior dimensão de sua realidade é apresentado na Tabela 1.

Tabela 1. Perfil das mulheres com crianças com suspeita ou confirmação de mal formação. Rio de Janeiro, 2016.

\begin{tabular}{|c|c|c|}
\hline Nome fictício & Idade & $\begin{array}{c}\text { Exposição à MFF ou possibilidade de início de vida com questões } \\
\text { de saúde específicas }\end{array}$ \\
\hline Frida & 35 & Microcefalia \\
\hline Clarice & 35 & $\begin{array}{c}\text { Hérnia diafragmática }+ \text { Transluscência nucal alterada }+ \text { suspeita de } \\
\text { Síndrome de Down }\end{array}$ \\
\hline Olga & 37 & Transluscência nucal alterada + confirmada Síndrome de Down \\
\hline Marta & 39 & Doença hemolítica + dilatação de pelve \\
\hline Dandara & 41 & Rim esquerdo não visualizado + Pé torto congênito \\
\hline Cecília & 41 & Esporotricose materna + múltiplas malformações \\
\hline Tarsila & 42 & Ressonância magnética na gravidez + mãe HIV positivo \\
\hline
\end{tabular}

Foram evidenciadas duas categorias de análise para apresentar os resultados do estudo:

1) 0 constrangimento de receber e compartilhar a notícia; e,

2) Receios quanto ao futuro.

\section{o constrangimento de receber $e$ compartilhar a notícia}

Mulheres gestando bebês com a possibilidade de malformação fetal são sujeitos com experiências prévias, que devem ser consideradas. Cabe pontuar que, ainda que não houvesse confirmação de malformação, percebeu-se que a suspeita já alterava as expectativas com relação ao nascimento da criança.

As pesquisadas demonstraram ter assimilado poucas informações quanto às condições de saúde do bebê, mesmo quando orientadas pela equipe de saúde, considerando que também estavam passando por um processo de investigação referente à saúde da criança. Contudo, o fato de haver alterações nos exames, já se configurava como motivo de tensão para essas mulheres.

Além disso, suas expectativas encontravam-se articuladas às suas bagagens individuais e as pressões sociais para o exercício de um determinado padrão de vivências. Em alguns casos, sequer existia o 
desejo da gestação e esta já foi uma notícia difícil, mesmo antes da suspeita de malformação:

Foi um baque, porque eu não queria... Nem o meu esposo, pela situação que a gente vive hoje, entendeu?! De saúde... Então, a gente não queria... Aí eu fui lá na Fiocruz falar que eu não queria e tudo, aí eles me mandaram pra cá. Quando cheguei aqui, eu falei também que eu não queria... Fui até lá na Maternidade porque eu tava sangrando, acho que é por causa do emocional, minha pressão tava 10x15, tava muito alto... (Tarsila, 42 anos).

Aquelas que planejaram a gestação relatam um duplo movimento: a felicidade pela realização de um desejo prévio e a decepção posterior com a notícia da malformação:

Aí ficamos muito felizes, muito. Até a hora que começaram a chegar os exames e começaram a chegar as complicações, né?! [...] Aí deu aquela... Foi aquele susto pra família, a gente balançou muito. (Olga, 37 anos).

Estas vivências estão muitas vezes associadas à um reconhecimento prévio por parte das mulheres dos preconceitos e dificuldades existentes de inserção destas crianças no âmbito da sociedade:

Nunca tinha tido nenhum tipo de contato com criança com Síndrome de Down, apesar de todo mundo achar bonitinho, falar: - "Ai, que fofo!", como se fosse um cachorrinho... [...] -"Mas eles são muito carinhosos!", entendeu?! [...]. Mas assim, eu fico muito assustada ainda (Olga, 37 anos).

Compartilhar a notícia também nem sempre se mostra como uma estratégia para a garantia de recebimento de apoio. Muitas vezes as mulheres se confrontam com manifestações de curiosidade e abordagens pouco respeitosas por parte de amigos e conhecidos. A despersonalização da mulher neste contexto e o foco voltado para a malformação do bebê podem ser elementos motivadores para que as gestantes redefinam a sua ação e adotem o silêncio como estratégia de proteção:

[...] A gente, sem querer, acha que contar pros outros ajuda... Não ajuda não, porque vira fofoca. E dentro da igreja mesmo que eu tava, que agora eu voltei pra outra, é... é assim: - "Oi! E o neném, quê que ele tem?" [...] É tipo assim... Eu tô bem, eu tô viva... Aí o neném... Tá bem! [...] Mas não... Tipo, "você morreu, que se dane"... Só tem o neném. "E o neném, que que ele tem?" Era só isso... Tipo, até hoje. Mas aí há uns tempinhos atrás, eu falei pro meu marido: "Não vou mais falar sobre isso, você pode avisar!". Se alguém me perguntar, eu vou falar assim: "Eu tô bem, muito obrigada!" (Clarice, 35 anos).

Estas vivências e suas observações prévias quanto à rotina de outras mulheres em igual condição, fazem com que estas gestantes apresentem sérias preocupações quanto à aceitação deste bebê no contexto social e quanto à possível sobrecarga e redimensionamento de sua vida futura.

\section{Receios quanto ao futuro}

$\mathrm{O}$ futuro tende a se firmar como um elemento doloroso. Estão presentes diversos componentes que remetem à preocupação com a condição específica de saúde da criança. A preocupação com a possibilidade de que a criança não possa desfrutar de uma vida independente no futuro é visível e concreta.

As reflexões sobre as condições de saúde são associadas ao estigma de que a criança possivelmente malformada e/ou cronicamente adoecida seja incapaz de exercer protagonismo e autonomia no futuro. Essa ideia está atrelada à dinâmica social predominante, que não valoriza a diversidade e é pautada na imediaticidade, na produção e no seguimento de um padrão de estética e de "ser saudável":

Só que a gente fica meio assim... que eu ia ter um filho, ele ia crescer, ia embora, ia casar, ia ser feliz com a vida dele, aí tem hora que a gente se pega: "Cara, esse meu filho [...], ele não vai casar, ele não vai embora". Então, a gente fica meio sem saber, assim... Não tem como saber (Olga, 37 anos).

A condição de saúde da criança não é o único fator de preocupação da mulher-mãe. Nestes casos, a estética da criança, independente da condição de saúde, também se configura como um expressivo elemento de aceitação ou não da criança por parte da sociedade e do pai do bebê:

Eu acho que, assim... Eu acho que pelos, assim... Os primeiros dias que nascer, se nascer uma criança bonita, perfeita... Acho que ele vai até ficar encantado. Mas se nascer com alguma coisa, ele vai largar de mão (Cecília, 41 anos).

0 medo de que a criança "nasça doente" tende a ser uma preocupação que interfere na aceitação da criança no núcleo familiar. E a aceitação ou não da criança pelos membros do grupo familiar tende a ser uma questão que provoca medo e insegurança nas mulheres, principalmente quando não correm expressões diretas de vínculo:

Meu esposo tava comigo. [...]. Até uma enfermeira conversou com a médica, porque eu tava muito abalada... Aí ela pegou e conversou comigo, que a criança podia não... Não vai nascer doente. [...]. Meu marido não tava 
aceitando até semana passada. Aí agora ele tá falando mais do bebê, tá dizendo que é uma menina. Meus filhos tão aceitando numa boa... (Tarsila, 42 anos).

As manifestações de apego e de afeto por parte dos familiares, também podem se constituir agentes de desconforto para estas gestantes. Nestes casos, o medo da decepção e o sofrimento que pode ser gerado nos familiares, também tende a estressar estas mulheres:

[...] Eles só falam de comprar as coisas pro neném, aí eu fico com medo da decepção, alguma coisa (Frida, 35 anos).

Estas duas percepções parecem estar atreladas ao fato das mulheres entenderem que é delas a responsabilidade principal pelos cuidados da criança, em especial das crianças com necessidades de saúde diferenciadas. Justificativas para os outros membros da família em função das necessidades de sustento ou de características de gênero parecem ser utilizadas para explicar este sentimento feminino de desapoio futuro:

[...] Eu vou ser sozinha de novo, porque a questão: minha filha tem que trabalhar pra manter a casa, né?! Se não, a gente pira... Filho homem é aquele negócio, né?! Chegou, deu um beijo e vai embora. É eu mesma... Vou ficar de novo na guerra de novo sozinha (Cecília, 41 anos).

Aí por melhor que seja seu marido, por melhor que seja sua família, sabe que quem vai segurar tudo é a mãe e eu já tenho plena capacidade de cuidar da minha filha $e$ sabendo que por mais que o pai é muito bom, companheiro, mas eu sei... Sei que vou precisar de mais força, mais tudo... Aí a gente tá nessa luta (Olga, 37 anos).

A tensão quanto aos desafios parece ser o motivador que justifica o uso de palavras como "luta" ou "guerra", quando se referem ao desafio de cuidar sozinha de uma criança. A conformidade em cuidar sozinha de uma criança com condições de saúde específicas são articuladas às experiências já existentes de maternidade, considerando que todas as entrevistadas tinham filhos anteriores.

As gestantes faziam um comparativo dos cuidados com os filhos anteriores e relembravam suas vivências e desafios, enfatizando o pouco ou nulo suporte que tiveram, especialmente quando se referiam à figura paterna. Estas perspectivas se desdobram nas expectativas de retorno ao mercado de trabalho:

[...] porque eu também não sei a condição que ele vai nascer... Que ele vai sair daqui e tal, então tudo baseado nisso... Conforme for também, se o caso for mais grave, $e$ tal, nem volto (Clarice, 35 anos).
Entende-se que quando a criança apresenta condições específicas de saúde, o desafio aumenta para o público feminino, uma vez que são poucos e custosos os aparatos sociais para o cuidado da criança com malformação e/ou adoecimento crônico e a mãe parece ser a pessoa que precisa abdicar de si mesma para o cuidado com esta criança. $\mathrm{E}$, ademais, advém a sobrecarga materna.

A dimensão da questão de gênero é nítida, uma vez que quando a mulher abandona o mercado de trabalho formal, ela se torna mais dependente financeiramente de sua rede de apoio, dos programas de transferência de renda e da renda do companheiro (para aquelas que são unidas). Entende-se que o abandono do mercado de trabalho formal por parte das mulheres pode impactar diretamente no exercício da sua autonomia.

\section{DISCUSSÃo}

O contato com o âmbito hospitalar e com os resultados dos exames contribuem para que essas mulheres tenham maior dimensão da realidade, ainda que esta não seja condizente com o ideal de criança saudável fomentado socialmente.

Em estudo realizado ${ }^{16}$ com mulheres grávidas de bebês com malformação, evidenciou-se que suas expectativas iam se modificando a medida que os resultados dos exames indicavam as condições específicas dessas crianças, condizente a pesquisa aqui apresentada.

Angústia, medo materno e incertezas em relação ao futuro, por ocasião de diagnóstico adverso em relação à saúde de seus filhos, constitui uma constante, bem como, a tristeza em função da perda do filho idealizado ${ }^{17-28}$.

Quanto ao constrangimento de revelar o possível diagnóstico de malformação para o pai da criança e para a família ampliada, um estudo $^{22}$ aponta que as mulheres, em um primeiro momento, omitiram a notícia de alguns membros familiares.

O peso do "coração de mãe" e do "instinto maternal" relatados como opressores dos direitos e da qualidade de vida das mulheres ${ }^{19,23,24}$, tendem a se reproduzir 
aqui, com as mulheres reconhecendo que será delas o maior desgaste para os cuidados com a criança ${ }^{23,24}$. Talvez este também seja um elemento que explique as dificuldades de contar a notícia para outras pessoas e a estratégia de silêncio como forma de defesa e proteção ${ }^{19}$.

Dificuldades relacionadas aos aspectos da ausência da família também já foi relatado ${ }^{17}$. A rede de apoio restrita destas mulheres ${ }^{20,24}$ pode explicar o afastamento feminino do mercado de trabalho formal17,21,23,24, o que impacta diretamente nas condições objetivas de vida das mulheres.

Este é um elemento fundamental, uma vez que o suporte social e familiar que a mulher recebe, pode impactar no modo como ela lida com a malformação ${ }^{28}$.

Uma novidade em relação a este estudo é que o afastamento dos outros filhos, para o cuidado do filho com questões específicas de saúde ${ }^{17}$ não parece figurar no imaginário das mulheres durante a gravidez. Os receios aqui relatados apresentam maior articulação com o futuro e com a independência da criança ${ }^{18,22,24,25,27}$, motivados talvez pela existência de filhos mais velhos, em virtude da idade das mulheres.

Mulheres com Idade materna avançada tendem a perceber que as reponsabilidades com a gravidez irão recair, sobretudo, nelas mesmas. Neste sentido, a maternidade de uma criança com necessidades específicas de saúde passa a ser entrave à inserção feminina na esfera pública ${ }^{23,24}$, havendo a necessidade de sua postergação e planejamentos para afastamento do mundo do trabalho.

\section{CONCLUSÃO}

0 presente estudo coloca em evidência a necessidade e a importância dos serviços de saúde conhecerem as demandas de mulheres em idade materna avançada que gestam bebês com diagnóstico suspeito ou confirmado de malformação fetal, para atende-las com base em suas necessidades. Conhecer as demandas deste grupo possibilita a oferta de serviços de maior qualidade e, que contemplem a realidade da população usuária.

\footnotetext{
É preciso refletir que não cabe limitar o exercício profissional à abordagem
}

biologicista, o que expressa a importância de um pré-natal que atue de forma integral à saúde, incorporando as esferas social, econômica, política e ideológica dessas mulheres e do território do qual elas vêm.

Apesar de estarem em idade avançada, estas mulheres têm necessidade de colocar suas dúvidas e de serem acolhidas, entendendo que a maternidade se configura como uma experiência ímpar, ainda que todas já tenham filhos anteriores.

Considerando as questões de saúde das crianças, evidencia-se a necessidade de um acompanhamento específico articulado à escuta qualificada e à construção de projetos de vida futuros para as próprias mulheres, uma vez que a criança malformada pode não corresponder aos padrões de saúde e estética impostos pela sociedade.

É necessário pensar que a idade materna avançada e a malformação fetal não estão descoladas do viés de gênero, uma vez que a mulher se configura como a principal cuidadora das crianças no Brasil e isso impacta diretamente em sua inserção nas esferas pública e privada. Por isso, nestes casos, os serviços de saúde devem estar dispostos a realizar um trabalho intensificado junto aos homens/pais, tanto no sentido de uma reflexão mais ampla sobre a questão de gênero, quanto na promoção de vínculos entre este homem e a criança.

Dar visibilidade a essa temática e trabalhá-la intensamente nos serviços de saúde, significa propiciar melhores condições de acesso deste público aos serviços e aos diversos espaços de convívio social, o que pode ter desdobramentos positivos nos indicadores de qualidade de vida das mulheres-mães e das crianças malformadas e/ou cronicamente adoecidas.

\section{REFERÊNCIAS}

1. Moreira MEL, Goldani MZ. A criança é o pai do homem: novos desafios para a área de saúde da criança. Ciênc Saúde Coletiva. 2010; 15(2):321-7.

2. Ministério da Saúde (Br). Secretaria de Atenção à Saúde, Departamento de Ações Programáticas Estratégicas. Gestação de alto 
risco: manual técnico. 5. ed. Brasília, DF: Ministério da Saúde; 2010.

3. Ministério da Saúde (Br). Departamento de Informática do SUS (DATASUS). Nascidos Vivos Brasil. [citado 18-11-2016]. Disponível em: http://datasus.saude.gov.br/sistemas-eaplicativos/eventos-v/sinasc-sistema-deinformacoes-de-nascidos-vivos

4. Gravena AAF, Sass A, Marcon SS, Pelloso SM. Resultados perinatais em gestações tardias. Rev Esc Enferm USP. 2012; 46(1):15-21.

5. Gonçalves ZR, Monteiro DLM. Complicações maternas em gestantes com idade avançada. Femina. 2012; 40(5):275-9.

6. Brito VRS, Sousa FS, Gadelha FH, Souto RQ, Rego ARF, França ISX. Malformações congênitas e fatores de risco materno em Campina Grande-Paraíba. Rev RENE. 2010; 11(2):27-36.

7. Martins AC, Melo FR. Gênero: dimensão fundamental da saúde humana. In: Silva LB, Ramos AS, organizadores. Serviço social, saúde e questões contemporâneas: reflexões críticas sobre a prática profissional. São Paulo: Papel Social; 2014. v. 1, p. 165-183.

8. Barbosa DC, Sousa FGM, Silva ACO, Silva IR, Silva DCM, Silva TP, et al. Sobrecarga do cuidado materno à criança com condição crônica. Cogitare Enferm. 2012; 17(3):492-7.

9. Barbosa DC, Sousa FGM, Silva ACO, Silva IR, Silva DCM, Silva TP. Funcionalidade de famílias de mães cuidadoras de filhos com condição crônica. Ciênc Cuid Saúde. 2011; 10(4):731-8.

10. Costa ASM, Britto MCA, Nóbrega SM, Vasconcelos MGL, Lima LS. Vivências de familiares de crianças e adolescentes com fibrose cística. Rev Bras Crescimento Desenvolv Hum. 2010; 20(2):217-27.

11. Organização Pan-Americana da Saúde. Prevenção e controle das enfermidades genéticas e dos defeitos congênitos: relatório de um grupo de consulta. Washington D.C: Organizaçao Pan-Americana da Saúde; 1984. 30 p. (OPAS. Publicação Científica, 460).

12. Vieira MA, Lima RAG. Crianças e adolescentes com doença crônica: convivendo com mudanças. Rev Latinoam Enferm. 2002; 10(4):552-60.

13. Bardin L. Análise de conteúdo. Lisboa: Edições 70; 2011.
14. Fontanella BJB, Ricas J, Turato ER. Amostragem por saturação em pesquisas qualitativas em saúde: contribuições teóricas. Cad Saúde Pública. 2008; 24(1):17-27.

15. Ministério da Saúde (Br). Conselho Nacional de Saúde. Resolução n. 466, de 12 de dezembro de 2012. Brasília: Ministério da Saúde; 2012.

16. Gomes AG, Piccinini CA. Impressões e sentimentos das gestantes sobre a ultrassonografia e suas implicações para a relação materno-fetal no contexto de anormalidade fetal. Psico. 2007; 38(1):67-76. 17. Cristino AC, Lopes RR, Diógenes KCBM. Sofrimento crônico: percepção de mães de crianças dependentes de ventilação mecânica. Rev Bras Promoç Saúde. 2015; 28(2):160-7.

18. Pereira-Silva NL, Almeida BR. Reações, sentimentos e expectativas de famílias de pessoas com necessidades educacionais especiais. Psicol Argum. 2014; 32(2):111-22.

19. Andrade MS. Sobre ser mãe/aprendente de sujeitos com necessidades educacionais especiais: acolhimento psicopedagógico do sofrimento materno. Constr Psicopedag. 2011; 19(19):66-81.

20. Barbosa TA, Lomba GO, Reis KMN, Braga $P P$, Alves GV. Rede de apoio e apoio social às crianças com necessidades especiais de saúde. Rev RENE. 2016; 17(1):60-6.

21. Anacleto TFM. As mudanças na sociabilidade materna com o advento da doença crônica em crianças: perspectivas e desafios para as políticas públicas. [Trabalho de conclusão de curso]. Rio de Janeiro, RJ: IFF; 2012. 30 p.

22. Sunelaitis RC, Arruda DC, Marcom SS. A repercussão de um diagnóstico de síndrome de Down no cotidiano familiar: perspectiva da mãe. Acta Paul Enferm. 2007; 20(3):264-71.

23. Costa ECL, Veloso RA, Feitosa JJM. Crianças portadoras de hidrocefalia: dificuldades e vivência das mães. Rev Interdisciplin. 2013; 6(1):71-9.

24. Almeida MI, Molina RCM, Vieira TMM, Higarashi IH, Marcom SS. O ser mãe de criança com doença crônica: realizando cuidados complexos. Esc Anna Nery Rev Enferm. 2006; 10(1):36-46. 
25. Gomes AG, Piccinini CA. Malformação no bebê e maternidade: aspectos teóricos e clínicos. Psicol Clín. 2010; 22(1):15-38.

26. Antunes MSC, Patrocínio C. A malformação do bebê: vivências psicológicas do casal. Psicol Saúde Doenças. 2007; 8(2):239-52.

27. Gomes AG, Piccinini CA, Prado LC. Psicoterapia pais-bebê no contexto de malformação do bebê: repercussões no olhar da mãe acerca do desenvolvimento do bebê. Rev Psiquiatr Rio Gd Sul. 2009; 31(2):95-104.
28. Vasconcelos L, Petean EBL. 0 impacto da malformação fetal: indicadores afetivos e estratégias de enfrentamento das gestantes. Psicol Saúde Doenças. 2009; 10(1):69-82.

CONTRIBUIÇÕES
Camila Rebouças Fernandes e Aline de
Carvalho Martins tiveram iguais
contribuições na concepção do projeto de
pesquisa, coleta e análise dos dados,
discussão dos resultados e elaboração do
artigo.

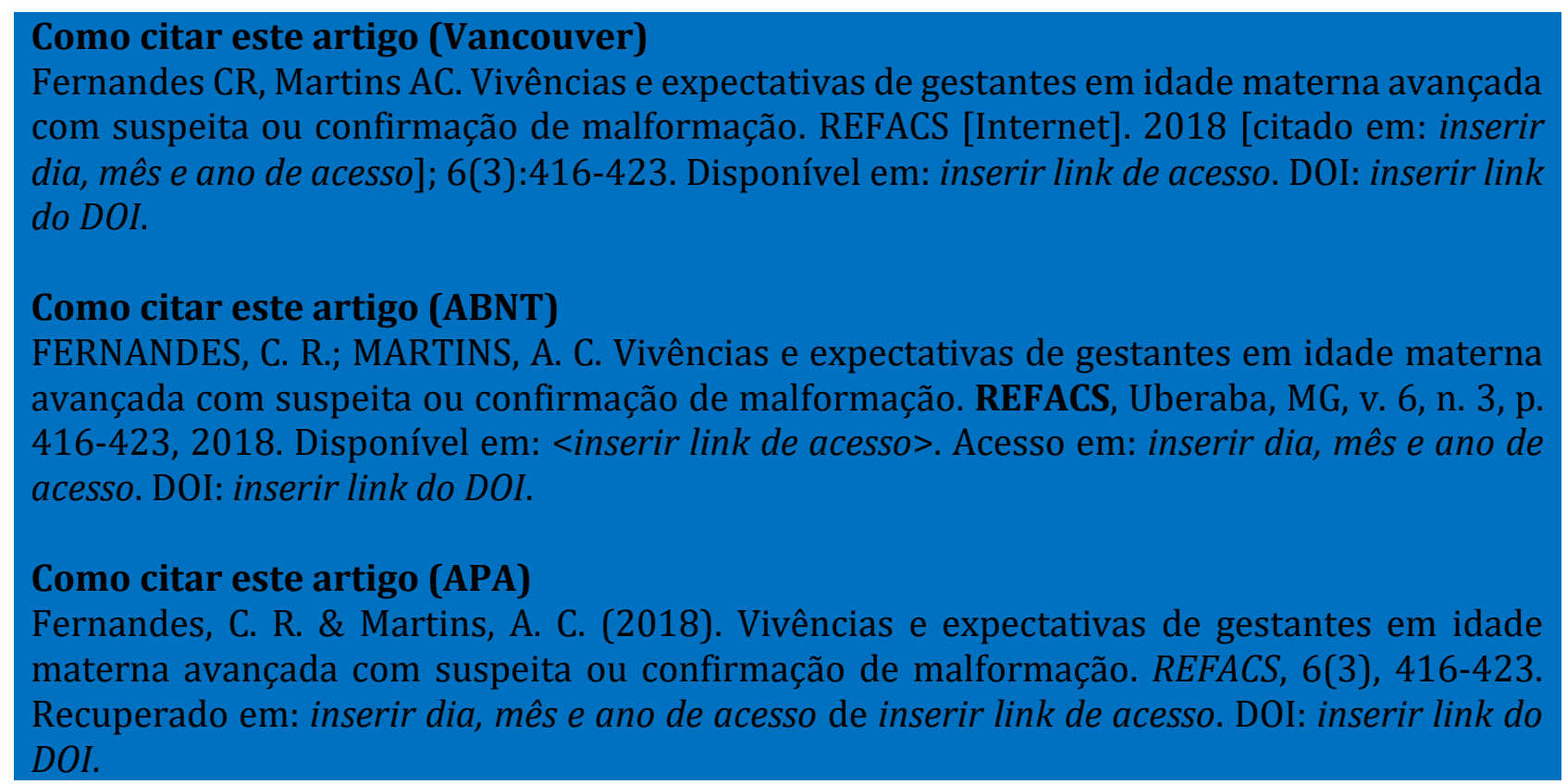

